\title{
Uveitis: diagnostic work-up. A literature review and recommendations from an expert committee
}

\author{
Pascal Sève ${ }^{1}$, Patrice Cacoub ${ }^{2}$, Bahram Bodaghi ${ }^{3}$, Salim Trad $^{4}$, Jérémie Sellam $^{5}$, David \\ Bellocq $^{6}$, Philip Bielefeld ${ }^{7}$, Damien Sène ${ }^{8}$, Gilles Kaplanski ${ }^{9}$, Dominique Monnet ${ }^{10}$, Antoine \\ Brézin $^{10}$, Michel Weber ${ }^{11}$, David Saadoun ${ }^{2}$, Christophe Chiquet ${ }^{12}$, Laurent Kodjikian ${ }^{5}$
}

${ }^{1}$ Service de Médecine Interne, Hôpital de la Croix-Rousse, Hospices Civils de Lyon, 103 grande rue de la Croix-Rousse, 69317 Lyon Cedex 04, France; Faculté de Médecine LyonSud, Université Claude Bernard-Lyon 1, France

${ }^{2}$ Service de Médecine Interne et Immunologie Clinique, Hôpital Pitié Salpetrière, Université Paris 6, AP-HP, Paris, France; DHU I2B, Inflammation, Immunopathology, Biotherapy, UPMC, Paris VI, France

${ }^{3}$ Service d'Ophtalmologie, Hôpital Pitié Salpetrière, Université Paris 6, AP-HP, Paris, France ${ }^{4}$ Service de Médecine Interne, Hôpital Ambroise Paré, 92100 Boulogne-Billancourt, France ${ }^{5}$ Service de Rhumatologie, Hôpital Saint-Antoine, AP-HP, UPMC Univ Paris 06, INSERM UMRS 938, DHU i2B, 75012 Paris, France

${ }^{6}$ Service d'Ophtalmologie, Hôpital Pitié Salpetrière, Université Paris 6, AP-HP, Paris, France

${ }^{7}$ Service de Médecine Interne et Maladies Systémiques, CHU Dijon Bourgogne, 21000 Dijon, France

${ }^{8}$ Service de Médecine Interne, Hôpital Lariboisère, AP-HP, GH Saint-Louis Lariboisière Fernand-Widal; Université Sorbonne Paris Cité- Paris Diderot, Paris, France 
${ }^{9}$ Service de Médecine Interne et Immunologie Clinique, Hôpital de la Conception, 147

Boulevard Baille, 13005 Marseille, France

${ }^{10}$ Service d'Ophtalmologie, Hôpital Cochin, Université Paris-Descartes, Assistance Publique

- Hôpitaux de Paris, 27 rue du Faubourg Saint-Jacques, 75014 Paris, France

${ }^{11}$ Service d'Ophtalmologie, Hôtel Dieu, Centre Hospitalo-Universitaire de Nantes, 1 place Alexis Ricordeau, 44093 cédex 1, France

${ }^{12}$ Service d'Ophtalmologie, Hôpital Albert Michalon, Université de Grenoble, F-38009, Grenoble, France

Corresponding author: Professeur Pascal Sève, Service de Médecine Interne, Hôpital de la Croix-Rousse, 103 grande rue de la Croix-Rousse, 69318 Lyon Cedex 04, France.

Tel: (33).4.26.73.26.27; Fax: (33).4.26.73.26.37; E-mail: pascal.seve@chu-lyon.fr

Key words: Epidemiology; Etiology; Uveitis; Diagnosis; Recommendations; Standardized Strategy 


\begin{abstract}
Purpose: Diagnosis of uveitis is difficult. Etiologic investigations should take into account the epidemiology of uveitis and should focus on the most severe forms of the disease and those which can be treated. This study was undertaken to establish recommendations for the diagnosis of uveitis.
\end{abstract}

Methods: Recommendations were developed by a multidisciplinary panel of 14 experts, including internists, ophthalmologists, and rheumatologists, and are based on a review of the literature and the results of the ULISSE study, which was the first prospective study to assess the efficacy of a standardized strategy for the etiologic diagnosis of uveitis. The following groups of patients are not included in these recommendations: children, immunocompromised patients, patients with severe retinal vasculitis, and those with specific eye diseases diagnosed by ophthalmologic examination only.

Results: Diagnosis should be guided by the medical history of the patient and physical examination. Serologic screening for syphilis is appropriate in all forms of uveitis. If uveitis is not diagnosed at this stage, investigations oriented by the anatomic characteristics of uveitis are proposed. These consist of assays for HLA-B27 (in unilateral acute anterior nongranulomatous uveitis), serum angiotensin-converting enzyme, interferon-gamma release, chest computed tomography (chronic uveitis), cerebral magnetic resonance imaging and anterior chamber tap with interleukin-10 analysis (intermediate or posterior uveitis in patients $>40$ years-old). Other investigations prescribed in the absence of orientation are usually unhelpful.

Conclusions: A strategy is proposed for the etiologic diagnosis of uveitis. The benefit of more invasive investigations remains to be determined. 


\section{Highlights}

- Etiologic diagnosis of uveitis should be guided by anatomic localization

- Syphilis serology is useful in all types of uveitis

- HLA-B27 typing is helpful in acute anterior non-granulomatous uveitis

- Measurement of ACE, IFN- $\gamma$ release, and chest CT scans are useful in chronic uveitis

- Cerebral MRI and ACT with IL-10 analysis help in intermediate or posterior uveitis 


\section{Abbreviations}

ACE: angiotensin-converting enzyme

ACT: anterior chamber tap

BAL: bronchoalveolar lavage

BMSG: biopsy of the minor salivary gland

CNS: central nervous system

CSF: cerebrospinal fluid

CRP: C-reactive protein

CT: computed tomography

ESR: erythrocyte sedimentation rate

FDG-PET-TDM: fluorodeoxyglucose positron emission tomography tomodensitometry

GWC: Goldmann-Witmer coefficient

IGRA: interferon-gamma release assay

IL: interleukin

MRI: magnetic resonance imaging

MS: multiple sclerosis

NPV: negative predictive value

PC: platelet count

PCR: polymerase chain reaction

PIOL: primary intraocular lymphoma

POCL: primary ocular-cerebral lymphoma

PPV: positive predictive value

TST: tuberculin skin test

WB: Western blot 


\section{Introduction}

Uveitis is defined as inflammation of the iris, ciliary body, vitreous, retina or choroid. Fundamental studies have shown genetic predispositions, T and B cell involvement, cytokines and chemokines signatures and signaling pathway as well as environmental influences in uveitis [1,2]. Its incidence is $17-52 / 100000$ person-years and the prevalence is $38-284 / 100$ 000 persons [3-5]. A study of medical insurance claims for 4 million individuals in the USA reported a prevalence of 133/100 000 persons, including a predominance of non-infectious uveitis (90.7\%) and anterior uveitis (80\%) [6] .

Uveitis is the cause of $5 \%$ of cases of legal blindness (central visual acuity of $1 / 10$ or less in the better eye ), mainly due to macular edema, ocular hypertonia, or retinal ischemia [7].

Around 60 causes of uveitis have been described and these can be classified into five groups (Table 1). The casual epidemiology varies depending on genetic and ethnic factors (e.g. HLA-B27 and sarcoidosis), environmental factors (e.g. tuberculosis), the definition of the disease (e.g. sarcoidosis), the inclusion of certain ophthalmologic entities in the idiopathic uveitis group (e.g. pars planitis), the paraclinical investigations carried out (e.g. nuclear imaging) and the method of recruitment of patients (e.g. tertiary centers). This explains the great heterogeneity in studies reported in the literature. The main etiologies reported are VogtKoyanagi-Harada disease and sarcoidosis in Japan [8,9], herpes virus in Tunisia [8], tuberculosis in India [10], and toxoplasmosis in South America [11,12]. In Western countries, approximately one-quarter of cases are linked to ophthalmologic disease, one-quarter to systemic disease fulfilling consensual diagnostic criteria, one-quarter to presumed systemic disease, and one-quarter have an unexplained origin [13]. Uveitis of unexplained origin, also known as idiopathic uveitis, represents $23-44 \%$ of cases according to recent studies from the West and Japan [9,14-23]. 
Knowledge of the epidemiology of uveitis is important since the diagnostic work-up should be oriented towards investigations for common diseases or diseases whose diagnosis may have therapeutic consequences.

Since 2005, uveitis has been classified anatomically according to the part of the eye affected (Figure 1), and the rate of onset and course of the disease [24]. Uveitis is 'limited' if it lasts for $<3$ months and 'persistent' if it is present for $>3$ months, and its onset may be sudden or insidious. The term acute uveitis is reserved for uveitis which occurs suddenly with a limited course (e.g. anterior uveitis associated with histocompatibility antigen (HLA)-B27). Recurrent uveitis is defined as episodes of uveitis separated by periods of remission of $>3$ months without treatment. Finally, uveitis is considered to be chronic if it persists for $>3$ months or reoccurs $<3$ months after stopping treatment. The etiologic distribution is directly linked to these factors.

Other ophthalmologic characteristics also orient the diagnosis such as the side affected, granulomatous character, existence of ocular hypertonia, synechia, retinal vasculitis (venous and/or arterial, occlusive) [25], single or multiple retinochoroidal lesions. Table 2 shows the main etiologies according to the anatomic site and semiology.

Currently, the few studies that have evaluated the value of complementary investigations in the etiologic diagnosis of uveitis have focused on one or more investigations for a specific uveitis type. The recommendations for diagnosis are mainly derived from experience and retrospective studies. When faced with similar clinical scenarios, experts have proposed a variety of complementary investigations [26]. The ULISSE study (Uvéites: évaluation cLInique et médico-économique d'une Stratégie Standardisée pour le diagnostic Etiologique) is the only controlled study to compare a 'standardized' 3-step approach (oriented assessment: investigations determined according to the ophthalmologic findings, 
possibility of prescribing 'open' examinations) to an 'open' strategy allowing the ophthalmologist to request any type of investigation [27].

In this report, we present the recommendations for the diagnosis of uveitis proposed by a group of experts (ophthalmologists, internists, and rheumatologists) following a review of data in the literature.

\section{Methods}

A literature review was carried out in May 2017 using the database Medline and the following keywords: 'uveitis' and 'diagnosis, recommendations, conjunctival biopsy, anterior chamber paracentesis (tap), vitreous analysis, vitrectomy, polymerase chain reaction, angiotensinconverting enzyme, lysozyme, tuberculin skin test, interferon-gamma release assay, HLAB27, HLA-A29, serology, chest X-rays, chest computed tomography, magnetic resonance imaging, minor salivary gland biopsy, bronchoalveolar lavage, lumbar puncture, cerebrospinal fluid, positron emission tomography, sarcoidosis, tuberculosis, intraocular lymphoma'.

\section{Open strategy versus oriented strategy}

Many authors have proposed a combination of investigations for the diagnosis of uveitis. Kijlstra et al. recommended the following investigations for all types of uveitis: platelet counts (PC), erythrocyte sedimentation rate (ESR), syphilis serology, HLA type, and chest Xrays [28]. Conversely, Rosenbaum and Smith [29] limited the paraclinical investigations for all types of uveitis to chest X-rays, and syphilis serology. Investigations for chronic uveitis by McClustey et al. consisted of chest X-rays, syphilis serology, and measurement of angiotensin-converting enzyme (ACE) [30]. Selmi recommended a more extensive assessment including immunologic tests (rheumatoid factor, anti-cyclic citrullinated peptide 
antibodies, anti-neutrophil cytoplasmic antibodies), and investigations for toxoplasma and herpes infection [31].

Harper et al. proposed carrying out tests which were determined by the anatomic type of uveitis [32]. These consisted of: (i) PC, ESR, syphilis serology, and HLA type - for a second episode of acute anterior uveitis; (ii) chest X-ray, measurement of ACE and lysozyme - for granulomatous uveitis; (iii) serology (syphilis, Lyme disease, bartonellosis, toxocariasis), measurement of ACE, and cerebral MRI - for intermediate uveitis; and (iv) PC, ESR, and toxoplasma serology - for pan-uveitis or posterior uveitis.

More recently, Jabs and Busingye [33] proposed that complementary investigations should be guided by the pre-test probability of etiology, the ophthalmologic signs and symptoms, and the therapeutic consequences. Only syphilis serology was recommended for all types of uveitis. The other investigations were targeted a detecting curable infectious or inflammatory etiologies likely to affect the state of health of the patient: Lyme serology (endemic area), tuberculin skin test (TST) and/or interferon-gamma (IFN- $\gamma$ ) release assay (IGRA), IFN- $\gamma$ production by T-lymphocytes in the presence of Mycobacteria tuberculosisspecific antigens (Eales disease, choroidal granuloma, or serpiginoid choroiditis), HLA-B27 (acute anterior non-granulomatous uveitis), chest X-ray, and liver assays (for the detection of sarcoidosis).

\section{Diagnostic value of complementary examinations}

Complementary examinations should be carried out to complete the ophthalmologic and physical picture. Intraocular specimens (aqueous humor, vitreous fluid) and extraophthalmologic examinations can be separated. The latter are particularly useful for the diagnosis of infections due to intracellular bacteria, systemic and neurologic diseases, and primary ocular-cerebral lymphoma (POCL). 


\subsection{Intraocular specimens}

Intraocular specimens can provide diagnostic proof of the infectious or cancerous origin of uveitis $[34,35]$. Depending on the type of uveitis and the presumptive diagnosis, different specimens are proposed: conjunctival biopsy, anterior chamber tap (ACT), or retinochoroidal biopsy.

\subsubsection{Conjunctival biopsy}

Examination of the conjunctiva is an important step in the diagnosis of uveitis. In sarcoidosis, clinical involvement of the conjunctiva is observed in $7-17 \%$ of cases with ocular involvement [36,37], in the form of small, yellowish, translucent, sub-conjunctival nodules. The sensitivity of conjunctival biopsy for the diagnosis of sarcoidosis is estimated to be 54\% in the sarcoidosis population who lack abnormal eye findings [38]. The rate of positivity of conjunctival biopsy in sarcoidosis patients, with or without ocular involvement, varies from $27-55 \%[39,40]$. Conjunctival nodules are more frequent in patients with sarcoidosis who are under 35-years of age [41].

\subsubsection{Anterior chamber tap (ACT)}

Depending on the clinical picture, ACT specimens will be sent to different laboratories for virological (PCR for herpes virus (HSV1-2, CMV, EBV, VZV) and rubella virus), bacteriological (blood culture, universal pan-bacterial PCR (16s RNA), mycological and parasitological (detection of fungal or Toxoplasma gondii antibodies and PCR), and biochemical (measurement of interleukins (IL)-10 and -6) analyses.

Harper et al. evaluated the usefulness of PCR (herpes virus, toxoplasmosis, and human T-cell lymphotropic virus 1) on aqueous humor specimens from 133 patients with 
chorioretinitis of suspected infectious origin. The sensitivity and specificity of PCR were $82 \%$ and $100 \%$, respectively, with $0 \%$ false positives and $14 \%$ false negatives [42]. Chronopoulos et al. recently reported a positivity rate of $50 \%$ for pathogen-related PCR in 45 patients with suspected infectious uveitis [43]. In patients with anterior uveitis, 53\% had positive viral PCR. In patients with posterior uveitis, 25\% were PCR-positive for Toxoplasma and 20\% were viral PCR-positive. According to two studies [43,44], analyses carried out on aqueous humor resulted in changes to the therapeutic management in $13-38 \%$ of patients. This percentage was dependent on the criteria used for the selection of patients.

In herpes uveitis, there is no consensus on the superiority of the Goldmann-Witmer coefficient (GWC) (47-85\%) [45] over PCR (90\%) [46]. For toxoplasmosis or toxocariasis, the test is usually carried out on aqueous humor with calculation of the GWC and/or Western blot (WB) for the detection of intraocular production of specific antibodies. A ratio of $>3$ is strongly suggestive of local production of anti-T. gondii antibodies indicating an intraocular infection [47]. The sensitivity of this method for the diagnosis of toxoplasmosis is estimated to be $70-80 \%$ and its specificity almost $100 \%$ [48][49]. The sensitivity of PCR for the detection of $T$. gondii DNA ranges from 31-46\% [49-51]. Combination of the three techniques $(\mathrm{GWC}+\mathrm{WB}+\mathrm{PCR})$ results in a sensitivity of $97 \%$ [49].

The sensitivity of PCR for the detection of M. tuberculosis varies from 33-77\% [45,[52][53] depending on the type of uveitis: 33\% for retinal vasculitis [54], 66\% for granulomatous pan-uveitis [54], 54\% for multifocal serpiginoid choroiditis [55], and 57\% for retinochoroidal lesions of suspected tuberculous origin [56].

In 1321 patients with anterior, intermediate, posterior, or pan-uveitis [57], universal 16s RNA PCR was positive for Bartonella $(\mathrm{n}=3 ; 0.2 \%)$, Coxiella $(\mathrm{n}=3 ; 0.2 \%)$ and T. whipplei $(n=10 ; 0.7 \%)$. The use of universal PCR or specific PCR (expensive) should therefore be discussed as second-line. 
In the case of suspected vitreoretinal lymphoma or primary intraocular lymphoma (PIOL), the concentrations of IL-10 and -6 can be estimated by ELISA in aqueous humor and vitreous fluid. High levels of IL-10 and an IL-10/IL-6 ratio of >1 are indicative of PIOL [5860]. An IL-10 concentration between 50 and $150 \mathrm{pg} / \mathrm{ml}$ in aqueous humor is strongly suggestive of PIOL [58,61]. The cytokine profile is identical in PIOL and POCL [62]. Conversely, cytokine levels are only slightly raised in T-cell lymphoma [63]. Similarly, no aqueous humor test is useful for the diagnosis of uveal lymphoma, which is not associated with an increase in intraocular cytokines.

\subsubsection{Diagnostic vitrectomy}

This is the reference technique for the diagnosis of intraocular lymphoma [64]. The diagnostic sensitivity of this test in PIOL ranges from 31-95\% [65-67]. Immunophenotyping by flux cytometry is a useful diagnostic method and complements cytological analysis. The majority of PIOLs are monoclonal B-cell lymphomas expressing CD19, CD20 and CD22, and kappa and gamma light chain immunoglobulins [68]. Germinal center markers such as BCL6 or CD10 may also be useful [69]. In the literature, immunolabeling for CD22 and CD20 had a sensitivity of $50 \%$ and $33 \%$, respectively, and a specificity of $94 \%$ and $89 \%$ [70]. The identification of lymphoma cells in cerebrospinal fluid (CSF) or in vitreous fluid from a patient with MRI signs of cerebral lymphoma may help to avoid stereotaxic cerebral biopsy [71].

Study of the rearrangement of immunoglobulin light chains by PCR is the most sensitive marker of monoclonality $(64-80 \%)$ [72,73]

Measurement of cytokine levels in pure or dilute vitreous fluid may orientate the diagnosis towards PIOL. The cut-off value for IL-10 positivity between 150 and $400 \mathrm{pg} / \mathrm{ml}$ in undiluted vitreous fluid is associated with a sensitivity of $80 \%$ and a specificity of $99 \%$ [58]. 
In diluted vitreous fluid, an IL-10 cut-off value of $50 \mathrm{pg} / \mathrm{ml}$ was associated with a sensitivity of $89 \%$ and specificity of $93 \%$. An IL-10/IL-6 ratio of $>1$ in patients with suspected PIOL is associated with a sensitivity of $74-93 \%$ and specificity of $75-100 \%$ $[72,74,75][71,73,74][60,72,74,75]$. The positive predictive value (PPV) is estimated to be $100 \%$ and the negative predictive value (NPV) $71 \%$ [74].

Microbiologic analysis of vitreous fluid by PCR is also useful for the diagnosis of infectious uveitis, with a sensitivity and specificity of $78 \%$ and $93 \%$, respectively. Combination of PCR analyses on aqueous humor and vitreous fluid has a sensitivity and specificity of $81 \%$ and $97 \%$, respectively, and is highest in immunosuppressed patients [42]. The diagnosis of Whipple's disease can be carried out by specific PCR as well as by cytological analysis of vitreous fluid by PCR [76].

\subsubsection{Retinochoroidal biopsy}

Transvitreous retinochoroidal biopsy can be used if previous methods have failed to diagnose PIOL [77,78]. Trans-scleral biopsy is proposed as a last resort. In addition to diagnosing PIOL, biopsy can help to correct a diagnosis of infectious origin (toxoplasmosis, tuberculosis...), non-hematologic malignancies (melanoma, carcinoma), or other lymphoid hemopathies (MALT lymphoma, lymphoblastic lymphoma) [79-82].

\subsection{Complementary blood investigations}

\subsubsection{Standard biologic assessment}

Le Scanff et al. [83] carried out a standard biologic assessment in $80 \%$ of patients with uveitis of unexplained origin, but blood ionogram, phosphocalcium assays, liver assays, and coagulation tests were rarely useful for diagnosis. In contrast, raised C-reactive protein (CRP) and ESR contributed to the etiologic diagnosis in $10 \%$ and $4 \%$ of cases, respectively. These 
results were confirmed by Bouillet et al. [84]. Lymphopenia (<1 Giga/l) was predictive of a diagnosis of sarcoidosis in $31 \%$ of patients [85].

\subsubsection{ACE and lysozyme}

Increased ACE levels and lysozyme are useful for the presumptive diagnosis of sarcoid uveitis. According to different studies, the sensitivity varies from 58-84\% for ACE and 60$78 \%$ for lysozyme, and the specificity from $83-95 \%$ for ACE and 76-95\% for lysozyme [86]. ACE has a lower specificity in younger patients, while treatment with an ACE inhibitor makes this test uninterpretable. Lysozyme may be raised, particularly in infectious uveitis [87]. Studies have demonstrated the interest of combining ACE and serum lysozyme assays with chest X-rays or thoracic scans for the diagnosis of sarcoid uveitis [88,89]. An elevation of these serum markers and/or the presence of mediastinal adenopathy was observed in all patients with histologically-proven sarcoidosis [88]. In comparison with ACE, Gundlach et al. recently reported better sensitivity (98\% vs. $22 \%$ ) and similar specificity (94\% vs. $99.5 \%)$ of measuring serum levels of soluble IL-2 receptor, which is a marker of T-lymphocyte activation, for the diagnosis of ocular sarcoidosis [90]. In many countries, this test is not part of the biologic assessment.

Following a retrospective study involving 300 patients with uveitis, Hadjadj recently showed that the existence of a 'string of pearls', multifocal choroiditis, lymphopenia, and/or raised ACE were associated with a diagnosis of ocular sarcoidosis (defined by the International Workshop on Ocular Sarcoidosis [91]), depending on the presence of these parameters: $4 \%$ of cases ( 0 parameter), $12 \%$ of cases ( 1 parameter), $57 \%$ of cases $(2$ parameters) and $100 \%$ of cases (3 parameters) [92].

\subsubsection{Tuberculin skin test (TST) and IGRA tests (IFN- $\gamma$ release assay)}


A diagnosis of proven tuberculous uveitis, established by demonstrating the presence of $M$. tuberculosis in the eye (culture, PCR, or biopsy), is rarely obtained in low endemic prevalence countries. In the absence of direct proof, the diagnosis is presumptive and is established à postériori based on a combination of clinical, radiologic, and biologic arguments, the exclusion of differential diagnoses and the response to anti-tubercular treatment [93]. The diagnosis relies on: (i) pulmonary imaging, which is significantly different depending on the epidemiologic characteristics of the region studied. In high endemic areas for tuberculosis, chest X-rays are frequently abnormal (76\% of cases [94]). In contrast, radiologic abnormalities are rarely observed in low endemic prevalence areas (14\% [95]); (ii) TST has a role to play in countries where BGC vaccination is not practiced, with a sensitivity and specificity for the diagnosis of tuberculous uveitis of $92-95 \%$ and $72-90 \%$, respectively [79,81]. Conversely, anergy orients the diagnosis towards sarcoidosis; (iii) IGRA tests, of which several are available (Quantiferon TB-Gold ${ }$, Quantiferon TB gold-in tube ${ }^{\circledR}$, Quantiplus ${ }^{\circledR}$ and Elispot $\left.{ }^{\circledR}\right)$, have been evaluated in comparison with TST in many studies. It has been proposed that they are used in combination with TST: the NPV of IGRA + TST varies from $79-84 \%[96,97]$. A recent study has shown that this strategy is the most effective in terms of cost-efficacy in comparison to the use of these tests alone or successively [98]. The discordance observed between IGRA and TST varies from 25\% [98] to 49\% [97]. Serpiginoid choroiditis and retinal vasculitis are most frequently associated with a positive IGRA test [94][99]. The proportion of positive IGRA tests, among the patients seen for the etiologic assessment of uveitis in a low endemic prevalence area is significantly higher than in the general population and is estimated at $23 \%$ [99] to $45 \%$ [100]. This high proportion of positive tests suggests an underestimation of tuberculous uveitis or the existence of a much larger proportion of false positives in this population [99,101]. A frequent situation, which 
should lead to caution, concerns patients with a history of treated tuberculosis and whose positivity in the IGRA test may confuse the etiologic orientation [100,102]

For the Quantiferon tests, a cut-off value of $1 \mathrm{IU} / \mathrm{ml}$ appears to be the most discriminating for the diagnosis of tuberculous uveitis [100,103].

In low endemic prevalence areas for tuberculosis, many retrospective studies and a case-control study evaluating Elispot (T-SPOT.TB) have demonstrated a sensitivity in the order of $80-94 \%$ and a specificity of $85 \%$ for the diagnosis of tuberculous uveitis [104]. In view of its better specificity, we propose carrying out an Elispot test in patients who are TST positive [105]. Given the absence of effect of the TST on Elispot test positivity, the latter test is only performed if the TST is positive (this avoids having to proceed further down the tuberculosis assessment in patients who are TST positive and Elispot negative (approximately $30 \%$ of patients who are TST positive) [105].

\subsection{Immunologic investigations}

A review of the literature has shown that the prevalence of lupus is $0.47 \%$ in patients with uveitis and the PPV of antinuclear antibodies for the diagnosis is <3\% [106]. Other studies have confirmed that immunologic investigations are rarely useful for the etiologic diagnosis of uveitis $[83,84]$.

\subsubsection{Serology}

Few studies have evaluated the usefulness of serology in uveitis without diagnostic orientation. Le Scanff et al. [83] reported that viral, bacterial and parasitic serology never contributed to the etiologic diagnosis of uveitis. There was no value in performing serology for Lyme disease systematically during uveitis (3-8\% seropositive, and low predictive value: $0-1 \%$ of diagnoses retained in all populations studied, often in corticoresistant uveitis) [107]. 
In our study, including 430 cases of uveitis, serology was positive in 34 cases (7.9\%), which is similar to the prevalence in the general population in France [108]. Finally, the diagnosis of Lyme disease-associated uveitis was retained in seven patients, in the absence of another etiology and after a response to antibiotherapy. In 5/7 cases, there were extra-ophthalmologic signs and symptoms and in all cases, corticoresistance.

In their serologic study, Drancourt et al. reported a prevalence of infection with slow growing organisms of $6 \%$ among 1321 patients with anterior (46\%), intermediate (22\%), posterior (21\%), or pan-uveitis (6\%)[57]. Serology was considered contributive for Bartonella (1.4\%), Borrelia burgdorferi (0.8\%), Chlamydia trachomatis (0.8\%), Coxiella burnetii $(0.7 \%)$, Leptospira $(0.15 \%)$, and Rickettsia $(0.6 \%)$.

\subsubsection{HLA type}

Only the determination of HLA-B27 is of interest for the diagnosis of acute anterior nongranulomatous uveitis in which this histocompatibility antigen is found in $50 \%$ of cases. Between 8 and $10 \%$ of Caucasians carry the HLA-B27 antigen [110,111]. A diagnosis of spondyloarthritis was established in $21-40 \%$ of patients who presented with acute anterior uveitis $[112,113]$. This examination should not be proposed in patients with intermediate or posterior uveitis [114]. During anterior uveitis, the presence of insidious spinal pain, usually inflammatory, should lead to the determination of HLA-B27 status and a radiologic examination: radiography, or MRI of the spine and sacroiliac joints [115]. MRI can demonstrate active inflammatory lesions (subchondral edema) and structural changes (bone erosions, sclerosis, fat infiltration) [116]. In two cohorts of 101 and 72 patients, Haroon et al. evaluated the interest of a diagnostic algorithm (DUET; Dublin Uveitis Evaluation Tool) to determine which patient, presenting with acute anterior uveitis, should be referred to a rheumatologist [112]. According to this algorithm, patients were referred to a rheumatologist 
if they were <45 years-old with spinal pain developing for $>3$ months, or arthralgia, if they: (i) were carriers of HLA-B27; or (ii) had psoriasis. The sensitivity of the algorithm for the diagnosis of spondyloarthritis was $96 \%$, and the specificity $97 \%$, while the positive and negative likelihood ratios were 41.5 and 0.03 , respectively.

\section{Radiologic examinations}

Sinus radiography, orthopantomograms, and imaging of the spine and sacroiliac joint are not useful in the absence of a clinically identified cause [83]. A recent study established the value of chest radiography for the etiologic diagnosis of uveitis: $15 \%$ patients had an abnormal examination [117]. The sensitivity and specificity were $64 \%$ and $91 \%$, respectively, for the diagnosis of histologically-proven sarcoidosis, while one patient had active tuberculosis.

\subsection{Thoracic scans}

The sensitivity of standard radiography for histologically-proven pulmonary sarcoidosis varies from $41-69 \%$ compared to a sensitivity of $91-100 \%$ for thoracic scans $[88,89,118,119]$. Thoracic scans are particularly useful in patients $>50$ or 60 years-old where conventional radiography is negative in half of cases $[88,119,120]$. Thoracic scans are considered evocative of sarcoidosis if they demonstrate bilateral hilar and/or mediastinal adenopathy, defined by a diameter along the small axis of $>1 \mathrm{~cm}$, pulmonary micronodules with a perilymphatic distribution, or other parenchymatous anomalies [121]. The existence of lymphopenia, raised ACE, 'chains of pearls', or multifocal choroiditis (at the back of the eye) is associated with these observations [92]. Thoracic scans can also reveal the sequelae of pulmonary tuberculosis in the form of scarring of the lung apex, pleural/parenchymatous calcifications, or unilateral calcified hilar adenopathy [122,123]. In a retrospective study of 300 patients, $6 \%$ had signs that were suggestive of latent tuberculosis on thoracic scans [92]. In another 
prospective series of 108 patients evaluated with the IGRA Elispot test [105], thoracic scans suggested acute or previous tuberculosis in only $3 \%$ of patients suspected to have ocular tuberculosis.

\subsection{Cerebral MRI}

Few studies have evaluated the value of systematic cerebral MRI [92,124]. Hadjadj et al. reported that only 3/15 patients who had an abnormal cerebral MRI among 168 patients undergoing this investigation presented with neurologic signs [92]. Several studies have shown a prevalence of multiple sclerosis (MS) ranging from 7-30\% in patients with intermediate uveitis, which led to authors to propose systematic cerebral MRI in these patients [32]. In our experience, the majority of patients who presented with uveitis and a demyelinating disease of the central nervous system (CNS) had a familial or personal history, or evocative neurologic signs [125]. For Petrushkin et al. this examination should not be proposed in the absence of a history or clinical signs suggestive of MS, in the absence of prognostic or therapeutic consequences [126]. However, these same authors recommended carrying out cerebral MRI before requesting tests for monoclonal anti-TNF $\alpha$ antibodies, in view of the risk of aggravation of a demyelinating disease [127]. For the same reasons, Wafefield et al. recommended carrying out cerebral MRI before anti-TNF $\alpha$ and anti-IL6 assays in patients with intermediate uveitis [128]. Cerebral MRI is generally proposed in the presence of neurologic signs suggestive of CNS involvement [129], suspected PIOL (with T1 sequences before and after injection of contrast material), or bilateral papillary edema (e.g. the search for cerebral thrombophlebitis during Behçet's disease). Medullary MRI should be carried out if MS is suspected and if there are signs of neurologic involvement (Lhermitte's sign, indolent intermittent claudication). 


\section{Invasive investigations}

\subsection{Biopsy of the minor salivary gland (BMSG)}

Two studies have recently reported the interest of BMSG for the histologic diagnosis of sarcoidosis in uveitis patients [130,131]. The positivity rate was 5.2 and $3 \%$, respectively, in these two studies. The sensitivity of BMSG in patients with proven sarcoidosis was 18 and $41 \%$, respectively. However, its positivity did not exclude tuberculosis [132].

\subsection{Bronchial fibroscopy and bronchoalveolar lavage (BAL)}

Several studies have reported the interest of BAL for the diagnosis of sarcoid uveitis [133]. BAL is considered to contribute when there is alveolar lymphocytosis $>15 \%$ with predominant CD4 cells (ratio CD4/CD8 of >3.5). The sensitivity of BAL was $63 \%$ in patients with uveitis during the course of histologically-proven sarcoidosis and the specificity was 75\% [118]. Lymphocytic alveolitis with predominant CD4 cells was demonstrated in the absence of radiologic abnormalities [92,133], but bronchial biopsy was never positive in this situation.

The sensitivity of bronchial biopsy varies from $42-61 \%$ for radiologic stage 0 and $43-$ $84 \%$ for stage I [134-136]. Echo-guided endobronchial or endo-esophageal fine-needle aspiration of the mediastinum may help to postpone mediastinoscopy [86]. These methods, which are generally well tolerated, result in a diagnostic gain of $22.5-41.4 \%$ in patients with suspected sarcoidosis compared to conventional bronchial biopsies.

\subsection{Lumbar puncture}

No study has evaluated the interest of analyzing CSF. Intrathecal production of immunoglobulins can be demonstrated in patients with intermediate idiopathic uveitis in the absence of inflammatory signs on cerebral or medullar MRI [137]. Hadjadj et al. reported 
abnormal CSF in $14 \%$ of 132 patients in whom this examination was carried out without describing the indications for or diagnostic contribution of this examination [92]. Only an abnormal MRI was associated with positivity of this examination, considered as contributive to the diagnosis of MS $(n=5)$, sarcoidosis $(n=4)$, Behçet disease $(n=2)$, Vogt-Koyanagi-Harada disease $(n=2)$, and lymphoma $(n=1)$.

\subsection{Positron-emission tomography (PET)}

In patients with unexplained uveitis or uveitis of sarcoid appearance, ${ }^{18}$ fluorodeoxyglucose PET tomodensitometry $\left({ }^{18}\right.$ FDG-PET-TDM) can reveal labeling suggestive of sarcoidosis (in particular lymph nodes) and guide biopsies. In a monocenter study of 54 patients with chronic uveitis suggestive of sarcoidosis, $31 \%$ of patients had labeling of the mediastinal lymph nodes, compatible with sarcoidosis, among whom $60 \%$ had normal thoracic scans [138]. The value of this test was higher in older patients (>56 years-old), in patients with posterior synechia and mediastinal adenopathy on the scans. The value of fine-needle mediastinal aspiration in patients with lymph node labeling on ${ }^{18}$ FDG-PET-TDM was not demonstrated.

\section{Proposed diagnostic work-up}

Only a few retrospective studies, mainly carried out on a small number of patients, have evaluated the usefulness of complementary investigations in the etiologic diagnosis of uveitis. Hadjadj et al. recently reported that complementary investigations were useful for the diagnosis of ocular sarcoidosis, in a selected population of 300 patients [92]. The ULISSE study is the first prospective study to evaluate this diagnostic approach (Figure 2) [27]. The first step in this study consisted of minimal assessment and investigations oriented according to clinical data. In the absence of factors orienting the diagnosis or a diagnosis following this step, complementary tests determined according to anatomic type of uveitis are proposed. 
This standardized strategy is drawn from the diagnostic strategy proposed by Harper in 2002 [32] and takes into account the conclusions of more recent studies and the advice of experts, who, for example, suggest an underestimation of sarcoidosis cases [86]. According to these investigations and in the absence of a diagnosis, 'open' investigations may be prescribed. A total of 903 patients were included and randomized in the ULISSE study [27]. After exclusion of patients who withdrew from the study and major deviations from the study protocol, 676 patients were analyzed: 303 in the standardized strategy arm and 373 in the open strategy arm. There were significantly more women and more cases of acute anterior uveitis in the standardized strategy arm while posterior uveitis was more frequent in the open arm. There was no significant difference in the proportion of diagnoses obtained in the two arms $(49.5 \%$ for the standardized strategy versus $54.4 \%$ for the open strategy), whereas approximately half as many complementary investigations were carried out in the standardized arm. In the standardized group, $97 \%$ of diagnoses were established following the first diagnostic step oriented according to clinical data $(75.7 \%)$ or simple paraclinical investigations according to the anatomic type of uveitis (21.3\%). Invasive complementary examinations (lumbar puncture, bronchial fibroscopy) proposed for chronic uveitis with involvement of the posterior segment or granulomatous uveitis were rarely carried out, due to the small number of patients concerned and the reticence of clinicians.

We recommend an etiologic assessment (Figure 2) initially oriented by clinical data, and then according to the anatomic characteristics of uveitis (Table 2), inspired by the strategy proposed in the ULISSE study. The following cases are excluded from these recommendations: pediatric uveitis, immunosuppressed patients [139], severe retinal vasculitis and ophthalmologic conditions whose diagnosis depends on an ophthalmologic examination. 
The minimal first-line assessment has a low predictive value (close to 10\%) (data submitted for publication) but is simple to carry out. Because of the therapeutic consequences, syphilis serology remains the only type of serologic test to carry out in a patient with uveitis, irrespective of the anatomic type. Toxoplasma serology is useful in cases where there is a chorioretinal focus and HSV, VZV and CMV serology are useful in the management of anterior or retinal uveitis, before ocular specimens are taken, due to their high NPV [140].

The frequency of presumed ocular tuberculosis ( $>5 \%$ of uveitis cases) in several European studies $[14,16,27]$ justifies including in vitro tests measuring IFN- $\gamma$ production by T-lymphocytes in patients with chronic uveitis in low endemic prevalence areas.

HLA-A29, present in $98-100 \%$ of retinochoroidal diseases [141], has a high NPV. Conversely, its PPV in posterior uveitis is low because it is present in 5-7\% of the general population. In our experience, tests for HLA-A29 may help orient the etiologic diagnosis in atypical presentations of the disease and open up the search for differential diagnoses (such as sarcoidosis) if this test is negative.

Cerebral or medullar MRI rarely contributes to the diagnosis of MS in patients whose oral questioning or neurologic examinations do support nervous system involvement. We therefore propose that this examination is reserved for patients $>40$ years-old with unexplained uveitis, during the search for cerebral lesions suggestive of PIOL. For the same reasons, we propose ACT with measurement of IL-10 in patients with intermediate uveitis.

In terms of patient assessment, other complementary examinations, which are more invasive or expensive, can be proposed in cases of unexplained uveitis if there are factors orienting the diagnosis (Table 4). BMSG is restricted to patients who present with mediastinal hilar adenopathy or raised ACE [130,131]. Lumbar puncture may be of interest in the following situations [92,142]: (i) suspicion of uveomeningitis, in particular Vogt-KoyanagiHarada disease (cytochemistry) [143]; (ii) bilateral papillary edema (after cerebral imaging); 
(iii) suspected MS (tests for intrathecal immunoglobulin production); (iv) suspected PIOL (cytology, immunophenotyping and measurement of IL-6 and IL-10) [75]; (v) syphilitic uveitis with involvement of the posterior segment (cytochemistry and serology); (vi) suspected neuro-Lyme disease (cytochemistry and serology). BAL should be discussed in unexplained uveitis involving the posterior segment to look for lymphocytic alveolitis, which will orientate the diagnosis towards sarcoidosis.

Investigations for antinuclear antibodies should be limited to uveitis in children with suspected idiopathic juvenile arthritis (anterior uveitis, non-granulomatous, synechia, hypertensive, insidious, or white eye) or in cases of peripheral polyarthritis.

\section{Conclusions}

The diagnostic approach to uveitis should be adapted to epidemiologic data and to the resources of the healthcare system. Ophthalmologic signs and symptoms observed by ophthalmologists and the findings of the clinical examination (anamnesis, physical examination) are crucial. A single prospective study has evaluated the value of a standardized strategy for the diagnosis of uveitis. The ULISSE study showed that the rate of diagnosis was comparable between a standardized strategy and an open strategy, with investigations requested in the absence of orientation of limited usefulness and, conversely, the benefit of simple para examinations.

We propose a diagnostic strategy based on ophthalmologic and clinical examination, and then, in the absence of orientation after this first step, complementary investigations guided by the anatomic type of uveitis. The value of invasive investigations (lumbar puncture, BAL) and/or more complex investigations (MRI and nuclear imaging) remains to be defined in prospective studies. In the future, endocular specimens combining the microbiologic 
techniques of multiplex PCR and measurement of cytokine or chemokine levels [144] could orientate the diagnosis in infectious uveitis or uveitis due to inflammatory disease.

\section{Acknowledgements}

\section{Funding sources}

This research did not receive any specific grant from funding agencies in the public, commercial, or not-for-profit sectors. 


\section{References}

[1. Bose T, Diedrichs-Möhring M, Wildner G. Dry eye disease and uveitis: A closer look at immune mechanisms in animal models of two ocular autoimmune diseases. Autoimmun Rev 2016;15:1181-92.

2. Bose T, Diedrichs-Möhring M, Wildner G. Corrigendum to "Dry eye disease and uveitis: A closer look at immune mechanisms in animal models of two ocular autoimmune diseases" [AUTREV 15-12 (2016) 1181-1192]. Autoimmun Rev 2017;16:555.

3. Prete M, Dammacco R, Fatone MC, Racanelli V. Autoimmune uveitis: clinical, pathogenetic, and therapeutic features. Clin Exp Med 2015;

4. Gritz DC, Wong IG. Incidence and prevalence of uveitis in Northern California; the Northern California Epidemiology of Uveitis Study. Ophthalmology 2004;111:491-500; discussion 500.

5. Rim TH, Kim SS, Ham D-I, Yu S-Y, Chung EJ, Lee SC, et al. Incidence and prevalence of uveitis in South Korea: a nationwide cohort study. Br J Ophthalmol 2017;

6. Thorne JE, Suhler E, Skup M, Tari S, Macaulay D, Chao J, et al. Prevalence of Noninfectious Uveitis in the United States: A Claims-Based Analysis. JAMA Ophthalmol 2016;134:1237-45.

7. Dick AD, Tundia N, Sorg R, Zhao C, Chao J, Joshi A, et al. Risk of Ocular Complications in Patients with Noninfectious Intermediate Uveitis, Posterior Uveitis, or Panuveitis. Ophthalmology 2016;123:655-62.

8. Kitamei H, Kitaichi N, Namba K, Kotake S, Goda C, Kitamura M, et al. Clinical features of intraocular inflammation in Hokkaido, Japan. Acta Ophthalmol 2009;87:424-8.

9. Keino H, Nakashima C, Watanabe T, Taki W, Hayakawa R, Sugitani A, et al. Frequency and clinical features of intraocular inflammation in Tokyo. Clin Experiment Ophthalmol 2009;37:595-601.

10. Dogra M, Singh R, Agarwal A, Sharma A, Singh SR, Gautam N, et al. Epidemiology of Uveitis in a Tertiary-care Referral Institute in North India. Ocul Immunol Inflamm 2016;1-8. 11. Gonzalez Fernandez D, Nascimento H, Nascimento C, Muccioli C, Belfort R. Uveitis in São Paulo, Brazil: 1053 New Patients in 15 Months. Ocul Immunol Inflamm 2016;1-6.

12. de-la-Torre A, López-Castillo CA, Rueda JC, Mantilla RD, Gómez-Marín JE, Anaya J-M. Clinical patterns of uveitis in two ophthalmology centres in Bogota, Colombia. Clin Experiment Ophthalmol 2009;37:458-66.

13. Abad S, Sève P, Dhote R, Brézin A-P. [Guidelines for the management of uveitis in internal medicine]. Rev Med Interne 2009;30:492-500.

14. Luca C, Raffaella A, Sylvia M, Valentina M, Fabiana V, Marco C, et al. Changes in patterns of uveitis at a tertiary referral center in Northern Italy: analysis of 990 consecutive cases. Int Ophthalmol 2017;

15. Bodaghi B, Cassoux N, Wechsler B, Hannouche D, Fardeau C, Papo T, et al. Chronic severe uveitis: etiology and visual outcome in 927 patients from a single center. Medicine (Baltimore) 2001;80:263-70.

16. Llorenç V, Mesquida M, Sainz de la Maza M, Keller J, Molins B, Espinosa G, et al. Epidemiology of uveitis in a Western urban multiethnic population. The challenge of globalization. Acta Ophthalmol 2015;93:561-7.

17. Jakob E, Reuland MS, Mackensen F, Harsch N, Fleckenstein M, Lorenz H-M, et al. Uveitis subtypes in a german interdisciplinary uveitis center--analysis of 1916 patients. $\mathbf{J}$ Rheumatol 2009;36:127-36.

18. Jones NP. The Manchester Uveitis Clinic: the first 3000 patients--epidemiology and casemix. Ocul Immunol Inflamm 2015;23:118-26. 
19. Grajewski RS, Caramoy A, Frank KF, Rubbert-Roth A, Fätkenheuer G, Kirchhof B, et al. Spectrum of Uveitis in A German Tertiary Center: Review of 474 Consecutive Patients. Ocul Immunol Inflamm 2015;1-7.

20. Zagora SL, Symes R, Yeung A, Yates W, Wakefield D, McCluskey PJ. Etiology and Clinical Features of Ocular Inflammatory Diseases in a Tertiary Referral Centre in Sydney, Australia. Ocul Immunol Inflamm 2016;1-8.

21. Oruc S, Kaplan AD, Galen M, Kaplan HJ. Uveitis referral pattern in a Midwest University Eye Center. Ocul Immunol Inflamm 2003;11:287-98.

22. Bajwa A, Osmanzada D, Osmanzada S, Khan I, Patrie J, Xin W, et al. Epidemiology of uveitis in the mid-Atlantic United States. Clin Ophthalmol 2015;9:889-901.

23. Barisani-Asenbauer T, Maca SM, Mejdoubi L, Emminger W, Machold K, Auer H. Uveitis- a rare disease often associated with systemic diseases and infections- a systematic review of 2619 patients. Orphanet J Rare Dis 2012;7:57.

24. Jabs DA, Nussenblatt RB, Rosenbaum JT, Standardization of Uveitis Nomenclature (SUN) Working Group. Standardization of uveitis nomenclature for reporting clinical data. Results of the First International Workshop. Am J Ophthalmol 2005;140:509-16.

25. Pelegrín L, Hernández-Rodríguez J, Espinosa G, Llorenç V, Sainz-de-la-Maza M, Fontenla JR, et al. Characterization of isolated retinal vasculitis. Analysis of a cohort from a single center and literature review. Autoimmun Rev 2017;16:237-43.

26. Lee CS, Randhawa S, Lee AY, Lam DL, Van Gelder RN. Patterns of Laboratory Testing Utilization Among Uveitis Specialists. Am J Ophthalmol 2016;170:161-7.

27. De Parisot A, Kodjikian L, Errera M-H, Sedira N, Heron E, Pérard L, et al. Randomized Controlled Trial Evaluating a Standardized Strategy for Uveitis Etiologic Diagnosis (ULISSE). Am J Ophthalmol 2017;178:176-85.

28. Kijlstra A. The value of laboratory testing in uveitis. Eye (Lond) 1990;4 ( Pt 5):732-6. 29. Smith JR, Rosenbaum JT. Management of uveitis: a rheumatologic perspective. Arthritis Rheum 2002;46:309-18.

30. McCluskey PJ, Towler HM, Lightman S. Management of chronic uveitis. BMJ 2000;320:555-8.

31. Selmi C. Diagnosis and classification of autoimmune uveitis. Autoimmun Rev 2014;13:591-4.

32. Harper S., Chorich L., Foster C. Diagnosis of uveitis. WB: Saunders company. Philadelphia: Foster CS, Vitale A; 2002. p. 79-103.

33. Jabs DA, Busingye J. Approach to the diagnosis of the uveitides. Am J Ophthalmol 2013;156:228-36.

34. Manku H, McCluskey P. Diagnostic vitreous biopsy in patients with uveitis: a useful investigation? Clin Experiment Ophthalmol 2005;33:604-10.

35. Rothova A, de Boer JH, Ten Dam-van Loon NH, Postma G, de Visser L, Zuurveen SJ, et al. Usefulness of aqueous humor analysis for the diagnosis of posterior uveitis.

Ophthalmology 2008;115:306-11.

36. Stavrou A, Foster S. Sarcoidosis. In : Foster S, Vitale A, editors. Diagnosis and treatment of uveitis. Philadelphia: W.B. Saunders Company, 2002, p. 710-25.

37. Jabs DA, Johns CJ. Ocular involvement in chronic sarcoidosis. Am J Ophthalmol 1986;102:297-301.

38. Korkmaz Ekren P, Mogulkoc N, Toreyin ZN, Egrilmez S, Veral A, Akalın T, et al. Conjunctival Biopsy as a First Choice to Confirm a Diagnosis of Sarcoidosis. Sarcoidosis Vasc Diffuse Lung Dis 2016;33:196-200.

39. Spaide RF, Ward DL. Conjunctival biopsy in the diagnosis of sarcoidosis. Br J

Ophthalmol 1990;74:469-71. 
40. Chung Y-M, Lin Y-C, Huang D-F, Hwang D-K, Ho DM. Conjunctival biopsy in sarcoidosis. J Chin Med Assoc 2006;69:472-7.

41. Hunter DG, Foster CS. Ocular manifestations of sarcoidosis. In: Albert DM, Jakobiec FA, eds. Principles and Practice of Ophthalmology. Philadelphia: Saunders, 1994:443-50.

42. Harper TW, Miller D, Schiffman JC, Davis JL. Polymerase chain reaction analysis of aqueous and vitreous specimens in the diagnosis of posterior segment infectious uveitis. Am J Ophthalmol 2009;147:140-7.e2.

43. Chronopoulos A, Roquelaure D, Souteyrand G, Seebach JD, Schutz JS, Thumann G. Aqueous humor polymerase chain reaction in uveitis - utility and safety. BMC Ophthalmol [Internet] 2016 [cited 2017 May 9];16. Available from:

http://www.ncbi.nlm.nih.gov/pmc/articles/PMC5084402/

44. Anwar Z, Galor A, Albini TA, Miller D, Perez V, Davis JL. The diagnostic utility of anterior chamber paracentesis with polymerase chain reaction in anterior uveitis. Am $\mathrm{J}$ Ophthalmol 2013;155:781-6.

45. Errera M-H, Goldschmidt P, Batellier L, Degorge S, Héron E, Laroche L, et al. Findings in Detection of Herpesviridae by Polymerase Chain Reaction and Intraocular Antibody Production in a Case Series of Anterior Uveitis. 2013;21:61-8.

46. Wensing B, Relvas LM, Caspers LE, Valentincic NV, Stunf S, de Groot-Mijnes JDF, et al. Comparison of rubella virus- and herpes virus-associated anterior uveitis: clinical manifestations and visual prognosis. Ophthalmology 2011;118:1905-10.

47. Desmonts G. Definitive serological diagnosis of ocular toxoplasmosis. Arch Ophthalmol 1966;76:839-51.

48. Kijlstra A, Luyendijk L, Baarsma GS, Rothova A, Schweitzer CM, Timmerman Z, et al. Aqueous humor analysis as a diagnostic tool in toxoplasma uveitis. Int Ophthalmol 1989;13:383-6.

49. Fekkar A, Bodaghi B, Touafek F, Le Hoang P, Mazier D, Paris L. Comparison of immunoblotting, calculation of the Goldmann-Witmer coefficient, and real-time PCR using aqueous humor samples for diagnosis of ocular toxoplasmosis. J Clin Microbiol 2008;46:1965-7.

50. Bou G, Figueroa MS, Martí-Belda P, Navas E, Guerrero A. Value of PCR for detection of Toxoplasma gondii in aqueous humor and blood samples from immunocompetent patients with ocular toxoplasmosis. J Clin Microbiol 1999;37:3465-8.

51. Brézin AP, Eqwuagu CE, Silveira C, Thulliez P, Martins MC, Mahdi RM, et al. Analysis of aqueous humor in ocular toxoplasmosis. N Engl J Med 1991;324:699.

52. Sharma K, Gupta V, Bansal R, Sharma A, Sharma M, Gupta A. Novel multi-targeted polymerase chain reaction for diagnosis of presumed tubercular uveitis. J Ophthalmic Inflamm Infect 2013;3:25.

53. Sharma K, Sharma A, Gupta A. Loop-mediated isothermal amplification for rapid diagnosis of tubercular uveitis - reply. JAMA Ophthalmol 2015;133:226.

54. Arora SK, Gupta V, Gupta A, Bambery P, Kapoor GS, Sehgal S. Diagnostic efficacy of polymerase chain reaction in granulomatous uveitis. Tuber Lung Dis 1999;79:229-33.

55. Mohan N, Balne PK, Panda KG, Sharma S, Basu S. Polymerase chain reaction evaluation of infectious multifocal serpiginoid choroiditis. Ocul Immunol Inflamm 2014;22:384-90.

56. Biswas J, Kazi MS, Agarwal VA, Alam MS, Therese KL. Polymerase chain reaction for Mycobacterium tuberculosis DNA detection from ocular fluids in patients with various types of choroiditis in a referral eye center in India. Indian J Ophthalmol 2016;64:904-7. 57. Drancourt M, Berger P, Terrada C, Bodaghi B, Conrath J, Raoult D, et al. High prevalence of fastidious bacteria in 1520 cases of uveitis of unknown etiology. Medicine (Baltimore) 2008;87:167-76. 
58. Cassoux N, Giron A, Bodaghi B, Tran THC, Baudet S, Davy F, et al. IL-10 measurement in aqueous humor for screening patients with suspicion of primary intraocular lymphoma. Invest Ophthalmol Vis Sci 2007;48:3253-9.

59. Whitcup SM, Stark-Vancs V, Wittes RE, Solomon D, Podgor MJ, Nussenblatt RB, et al. Association of interleukin 10 in the vitreous and cerebrospinal fluid and primary central nervous system lymphoma. Arch Ophthalmol 1997;115:1157-60.

60. Pochat-Cotilloux, Céline, Bienvenu J, Nguyen A, Ohanessian R, Ghésquières H, Sève P, et al. Use of a threshold of Interleukin-10 and IL-10/IL-6 ratio in ocular samples for the screening of vitreoretinal lymphoma.

61. Merle-Béral H, Davi F, Cassoux N, Baudet S, Colin C, Gourdet T, et al. Biological diagnosis of primary intraocular lymphoma. Br J Haematol 2004;124:469-73.

62. Fisson S, Ouakrim H, Touitou V, Baudet S, Ben Abdelwahed R, Donnou S, et al. Cytokine profile in human eyes: contribution of a new cytokine combination for differential diagnosis between intraocular lymphoma or uveitis. PLoS ONE 2013;8:e52385.

63. Cassoux N, Merle-Beral H, Lehoang P, Herbort C, Chan CC. Interleukin-10 and intraocular-central nervous system lymphoma. Ophthalmology 2001;108:426-7.

64. Fend F, Ferreri AJM, Coupland SE. How we diagnose and treat vitreoretinal lymphoma.

Br J Haematol 2016;173:680-92.

65. Hoffman PM, McKelvie P, Hall AJ, Stawell RJ, Santamaria JD. Intraocular lymphoma: a series of 14 patients with clinicopathological features and treatment outcomes. Eye (Lond) 2003;17:513-21.

66. Coupland SE, Bechrakis NE, Anastassiou G, Foerster AMH, Heiligenhaus A, Pleyer U, et al. Evaluation of vitrectomy specimens and chorioretinal biopsies in the diagnosis of primary intraocular lymphoma in patients with Masquerade syndrome. Graefes Arch Clin Exp Ophthalmol 2003;241:860-70.

67. Davis JL, Viciana AL, Ruiz P. Diagnosis of intraocular lymphoma by flow cytometry. Am J Ophthalmol 1997;124:362-72.

68. Kodjikian L, Pérignon S, Sève P, Guesquières H. Lymphome intra-oculaire. Rapport de la Société Française d'Ophtalmologie, Antoine Brezin. Masson, 2010: 565-586.

69. Coupland SE, Loddenkemper C, Smith JR, Braziel RM, Charlotte F, Anagnostopoulos I, et al. Expression of Immunoglobulin Transcription Factors in Primary Intraocular Lymphoma and Primary Central Nervous System Lymphoma. Invest Ophthalmol Vis Sci 2005;46:395764.

70. Margolis R. Diagnostic vitrectomy for the diagnosis and management of posterior uveitis of unknown etiology. Curr Opin Ophthalmol 2008;19:218-24.

71. Hoang-Xuan K, Bessell E, Bromberg J, Hottinger AF, Preusser M, Rudà R, et al.

Diagnosis and treatment of primary CNS lymphoma in immunocompetent patients: guidelines from the European Association for Neuro-Oncology. Lancet Oncol 2015;16:e322-32.

72. Kimura K, Usui Y, Goto H, Japanese Intraocular Lymphoma Study Group. Clinical features and diagnostic significance of the intraocular fluid of 217 patients with intraocular lymphoma. Jpn J Ophthalmol 2012;56:383-9.

73. Baehring JM, Androudi S, Longtine JJ, Betensky RA, Sklar J, Foster CS, et al. Analysis of clonal immunoglobulin heavy chain rearrangements in ocular lymphoma. Cancer 2005;104:591-7.

74. Sugita S, Takase H, Sugamoto Y, Arai A, Miura O, Mochizuki M. Diagnosis of intraocular lymphoma by polymerase chain reaction analysis and cytokine profiling of the vitreous fluid. Jpn J Ophthalmol 2009;53:209-14.

75. Wang Y, Shen D, Wang VM, Sen HN, Chan C-C. Molecular biomarkers for the diagnosis of primary vitreoretinal lymphoma. Int J Mol Sci 2011;12:5684-97. 
76. Touitou V, Fenollar F, Cassoux N, Merle-Beral H, LeHoang P, Amoura Z, et al. Ocular Whipple's Disease: Therapeutic Strategy and Long-Term Follow-Up. Ophthalmology 2012;119:1465-9.

77. Mudhar HS, Sheard R. Diagnostic cellular yield is superior with full pars plana vitrectomy compared with core vitreous biopsy. Eye (Lond) 2013;27:50-5.

78. Davis JL, Miller DM, Ruiz P. Diagnostic testing of vitrectomy specimens. Am J

Ophthalmol 2005;140:822-9.

79. Cole CJ, Kwan AS, Laidlaw D a. H, Aylward GW. A new technique of combined retinal and choroidal biopsy. Br J Ophthalmol 2008;92:1357-60.

80. Mastropasqua R, Thaung C, Pavesio C, Lightman S, Westcott M, Okhravi N, et al. The Role of Chorioretinal Biopsy in the Diagnosis of Intraocular Lymphoma. Am J Ophthalmol 2015;160:1127-32.e1.

81. Kvanta A, Seregard S, Kopp ED, All-Ericsson C, Landau I, Berglin L. Choroidal biopsies for intraocular tumors of indeterminate origin. Am J Ophthalmol 2005;140:1002-6.

82. Lim LL, Suhler EB, Rosenbaum JT, Wilson DJ. The role of choroidal and retinal biopsies in the diagnosis and management of atypical presentations of uveitis. Trans Am Ophthalmol Soc 2005;103:84-91; discussion 91-2.

83. Le Scanff J, Sève P, Kodjikian L, Grange J-D, Broussolle C. Apport de la consultation interniste dans le diagnostic étiologique des uvéites. Étude comparative portant sur 66 patients. 2006;27:671-8.

84. Bouillet L, Sarrot-Reynauld F, Gonzalvez B, Massot C, Romanet J, Mouillon M. [Diagnostic strategy in uveitis: a prospective study in 125 cases]. J Fr Ophtalmol 2000;23:569-75.

85. Jones NP, Tsierkezou L, Patton N. Lymphopenia as a predictor of sarcoidosis in patients with uveitis. Br J Ophthalmol 2016;

86. Jamilloux Y, Kodjikian L, Broussolle C, Sève P. Sarcoidosis and uveitis. Autoimmun Rev 2014;13:840-9.

87. Sahin O, Ziaei A, Karaismailoğlu E, Taheri N. The serum angiotensin converting enzyme and lysozyme levels in patients with ocular involvement of autoimmune and infectious diseases. BMC Ophthalmol 2016;16:19.

88. Febvay C, Kodjikian L, Maucort-Boulch D, Perard L, Iwaz J, Jamilloux Y, et al. Clinical features and diagnostic evaluation of 83 biopsy-proven sarcoid uveitis cases. Br J Ophthalmol 2015;99:1372-6.

89. Birnbaum AD, Oh FS, Chakrabarti A, Tessler HH, Goldstein DA. Clinical features and diagnostic evaluation of biopsy-proven ocular sarcoidosis. Arch Ophthalmol 2011;129:40913.

90. Gundlach E, Hoffmann MM, Prasse A, Heinzelmann S, Ness T. Interleukin-2 Receptor and Angiotensin-Converting Enzyme as Markers for Ocular Sarcoidosis. PLoS ONE 2016;11:e0147258.

91. Herbort CP, Rao NA, Mochizuki M, members of Scientific Committee of First International Workshop on Ocular Sarcoidosis. International criteria for the diagnosis of ocular sarcoidosis: results of the first International Workshop On Ocular Sarcoidosis (IWOS). Ocul Immunol Inflamm 2009;17:160-9.

92. Hadjadj J, Dechartres A, Chapron T, Assala M, Salah S, Dunogué B, et al. Relevance of diagnostic investigations in patients with uveitis: Retrospective cohort study on 300 patients. Autoimmun Rev 2017;

93. Gupta V, Gupta A, Rao NA. Intraocular tuberculosis--an update. Surv Ophthalmol 2007;52:561-87. 
94. Babu K, Bhat SS, Philips M, Subbakrishna DK. Review of Results of QuantiFERON TB Gold Test in Presumed Ocular Tuberculosis in a South Indian Patient Population. Ocul Immunol Inflamm 2016;24:498-502.

95. Agrawal R, Gupta B, Gonzalez-Lopez JJ, Rahman F, Phatak S, Triantafyllopoulou I, et al. The role of anti-tubercular therapy in patients with presumed ocular tuberculosis. Ocul Immunol Inflamm 2015;23:40-6.

96. Ang M, Htoon HM, Chee S-P. Diagnosis of tuberculous uveitis: clinical application of an interferon-gamma release assay. Ophthalmology 2009;116:1391-6.

97. Ang M, Wong W, Ngan CCL, Chee S-P. Interferon-gamma release assay as a diagnostic test for tuberculosis-associated uveitis. Eye (Lond) 2012;26:658-65.

98. Ang M, Nguyen HV, Kiew SY, Chen S, Chee S-P, Finkelstein E. Cost-effectiveness of alternative strategies for interferon- $\gamma$ release assays and tuberculin skin test in tuberculous uveitis. 2015; bjophthalmol - 2014.

99. La Distia Nora R, van Velthoven MEJ, Ten Dam-van Loon NH, Misotten T, Bakker M, van Hagen MP, et al. Clinical manifestations of patients with intraocular inflammation and positive QuantiFERON-TB gold in-tube test in a country nonendemic for tuberculosis. Am J Ophthalmol 2014;157:754-61.

100. Gineys R, Bodaghi B, Carcelain G, Cassoux N, Boutin LTH, Amoura Z, et al. QuantiFERON-TB gold cut-off value: implications for the management of tuberculosisrelated ocular inflammation. Am J Ophthalmol 2011;152:433-40.e1.

101. Jakob E, Max R, Zimmermann S, Dalpke AH, Alle W, Becker M, et al. Three years of experience with QuantiFERON-TB gold testing in patients with uveitis. Ocul Immunol Inflamm 2014;22:478-84.

102. Itty S, Bakri SJ, Pulido JS, Herman DC, Faia LJ, Tufty GT, et al. Initial results of QuantiFERON-TB Gold testing in patients with uveitis. Eye (Lond) 2009;23:904-9.

103. Agrawal R, Gonzalez-Lopez JJ, Nobre-Cardoso J, Gupta B, Grant R, Addison PKF, et al. Predictive factors for treatment failure in patients with presumed ocular tuberculosis in an area of low endemic prevalence. Br J Ophthalmol 2016;100:348-55.

104. Urzua CA, Liberman P, Abuauad S, Sabat P, Castiglione E, Beltran-Videla MA, et al. Evaluation of the Accuracy of T-SPOT.TB for the Diagnosis of Ocular Tuberculosis in a BCG-vaccinated, Non-endemic Population. Ocul Immunol Inflamm 2016;1-5.

105. Ball P-M, Pernollet M, Bouillet L, Maurin M, Pavese P, Quesada J-L, et al. Usefulness of an in-vitro tuberculosis interferon- \&\#x03B3; release assay (T-SPOT.TB) in the first-line check-up of uveitis patients. Ann Med 2010;42:546-54.

106. Gallagher K, Viswanathan A, Okhravi N. Association of systemic lupus erythematosus with uveitis. JAMA Ophthalmol 2015;133:1190-3.

107. Kazi H, de Groot-Mijnes JDF, Ten Dam-van Loon NH, Ossewaarde-van Norel J, Oosterheert JJ, de Boer JH. No value for routine serological screening for B. burgdorferi in patients with uveitis in the Netherlands. Am J Ophthalmol 2016;

108. Bernard A, Kodjikian L, Abukhashabh A, Roure-Sobas C, Boibieux A, Denis P, et al. Diagnosis of Lyme associated uveitis: value of serological testing in a tertiary center.

109. Drancourt M, Berger P, Terrada C, Bodaghi B, Conrath J, Raoult D, et al. High prevalence of fastidious bacteria in 1520 cases of uveitis of unknown etiology. Medicine (Baltimore) 2008;87:167-76.

110. Kopplin LJ, Mount G, Suhler EB. Review for Disease of the Year: Epidemiology of HLA-B27 Associated Ocular Disorders. Ocul Immunol Inflamm 2016;24:470-5.

111. Costantino F, Talpin A, Said-Nahal R, Goldberg M, Henny J, Chiocchia G, et al. Prevalence of spondyloarthritis in reference to HLA-B27 in the French population: results of the GAZEL cohort. Ann Rheum Dis 2015;74:689-93. 
112. Haroon M, O’Rourke M, Ramasamy P, Murphy CC, FitzGerald O. A novel evidencebased detection of undiagnosed spondyloarthritis in patients presenting with acute anterior uveitis: the DUET (Dublin Uveitis Evaluation Tool). Ann Rheum Dis 2015;74:1990-5. 113. Wach J, Maucort-Boulch D, Kodjikian L, Iwaz J, Broussolle C, Sève P. Acute anterior uveitis and undiagnosed spondyloarthritis: usefulness of Berlin criteria. Graefes Arch Clin Exp Ophthalmol 2015;253:115-20.

114. Huhtinen M, Karma A. HLA-B27 typing in the categorisation of uveitis in a HLA-B27 rich population. Br J Ophthalmol 2000;84:413-6.

115. Poddubnyy D, van Tubergen A, Landewé R, Sieper J, van der Heijde D, Assessment of SpondyloArthritis international Society (ASAS). Development of an ASAS-endorsed recommendation for the early referral of patients with a suspicion of axial spondyloarthritis. Ann Rheum Dis 2015;74:1483-7.

116. Mandl P, Navarro-Compán V, Terslev L, Aegerter P, van der Heijde D, D'Agostino MA, et al. EULAR recommendations for the use of imaging in the diagnosis and management of spondyloarthritis in clinical practice. Ann Rheum Dis 2015;74:1327-39.

117. Groen F, van Laar JAM, Rothova A. Chest Radiographic Screening for Sarcoidosis in the Diagnosis of Patients with Active Uveitis. Ann Am Thorac Soc 2017;14:912-8.

118. Takada K, Matsumoto S, Kojima E, Iwata S, Tanaka K. Diagnostic management of patients with suspected ocular sarcoidosis. J Thorac Dis 2013;5:135-40.

119. Chung Y-M, Lin Y-C, Liu Y-T, Chang S-C, Liu H-N, Hsu W-H. Uveitis with biopsyproven sarcoidosis in Chinese--a study of 60 patients in a uveitis clinic over a period of 20 years. J Chin Med Assoc 2007;70:492-6.

120. Kaiser PK, Lowder CY, Sullivan P, Sanislo SR, Kosmorsky GS, Meziane MA, et al. Chest computerized tomography in the evaluation of uveitis in elderly women. Am J Ophthalmol 2002;133:499-505.

121. Clement DS, Postma G, Rothova A, Grutters JC, Prokop M, de Jong PA. Intraocular sarcoidosis: association of clinical characteristics of uveitis with positive chest high-resolution computed tomography findings. Br J Ophthalmol 2010;94:219-22.

122. Lee J-J, Chong P-Y, Lin C-B, Hsu A-H, Lee C-C. High resolution chest CT in patients with pulmonary tuberculosis: characteristic findings before and after antituberculous therapy. Eur J Radiol 2008;67:100-4.

123. Andreu J, Cáceres J, Pallisa E, Martinez-Rodriguez M. Radiological manifestations of pulmonary tuberculosis. Eur J Radiol 2004;51:139-49.

124. Gil H, Fery-Blanco C, Schwartz C, Meaux-Ruault N, Tisserand G, Delbosc B, et al. [Contribution of cerebral magnetic resonance imaging to etiological investigation of uveitis]. Rev Med Interne 2014;35:790-3.

125. Le Scanff J, Sève P, Renoux C, Broussolle C, Confavreux C, Vukusic S. Uveitis associated with multiple sclerosis. Mult Scler 2008;14:415-7.

126. Petrushkin H, Kidd D, Pavesio C. Intermediate uveitis and multiple sclerosis: to scan or not to scan. Br J Ophthalmol 2015;99:1591-3.

127. Kaltsonoudis E, Voulgari PV, Konitsiotis S, Drosos AA. Demyelination and other neurological adverse events after anti-TNF therapy. Autoimmun Rev 2014;13:54-8.

128. Wakefield D, McCluskey P, Wildner G, Thurau S, Carr G, Chee S-P, et al. Inflammatory eye disease: Pre-treatment assessment of patients prior to commencing immunosuppressive and biologic therapy: Recommendations from an expert committee. Autoimmun Rev 2017; 16:213-22.

129. Rizzo G, Licchetta L, Scaglione C, Buttiglione M, Capellari S, Martinelli P, et al. Behçet disease presenting with movement disorders and antibasal ganglia antibodies. Autoimmun Rev 2016;15:287-8. 
130. Blaise P, Fardeau C, Chapelon C, Bodaghi B, Le Hoang P. Minor salivary gland biopsy in diagnosing ocular sarcoidosis. 2011;95:1731-4.

131. Bernard C, Kodjikian L, Bancel B, Isaac S, Broussolle C, Seve P. Ocular sarcoidosis: when should labial salivary gland biopsy be performed? Graefes Arch Clin Exp Ophthalmol 2013;251:855-60.

132. Delcey V, Morgand M, Lopes A, Mouly S, Jarrin I, Sellier P, et al. [Prevalence of granulomatous lesions in minor salivary gland biopsy in a case series of 65 patients with tuberculosis]. Rev Med Interne 2016;37:80-3.

133. Takahashi T, Azuma A, Abe S, Kawanami O, Ohara K, Kudoh S. Significance of lymphocytosis in bronchoalveolar lavage in suspected ocular sarcoidosis. Eur Respir J 2001;18:515-21.

134. Ohmichi M. [Histologic diagnosis of sarcoidosis]. Nippon Rinsho 2002;60:1759-65. 135. Ohara K, Okubo A, Kamata K, Sasaki H, Kobayashi J, Kitamura S. Transbronchial lung biopsy in the diagnosis of suspected ocular sarcoidosis. Arch Ophthalmol 1993;111:642-4.

136. De Boer S, Milne DG, Zeng I, Wilsher ML. Does CT scanning predict the likelihood of a positive transbronchial biopsy in sarcoidosis? Thorax 2009;64:436-9.

137. Le Roux K, Kodjikian L, Marignier R, Bancel J, Broussolle C, Sève P. Intrathecal synthesis of immunoglobulins in patients with unexplained intermediate uveitis. Ocul Immunol Inflamm 2011;19:26-31.

138. Rahmi A, Deshayes E, Maucort-Boulch D, Varron L, Grange JD, Kodjikian L, et al. Intraocular sarcoidosis: association of clinical characteristics of uveitis with findings from 18F-labelled fluorodeoxyglucose positron emission tomography. Br J Ophthalmol 2012;96:99-103.

139. De Parisot A, Jamilloux Y, Kodjikian L, Errera M-H, Sedira N, Heron E, et al. Randomized Controlled Trial Evaluating a Standardized Strategy for Uveitis Etiologic Diagnosis (ULISSE). Am J Ophthalmol 2017;

140. Bonfioli AA, Orefice F. Toxoplasmosis. Semin Ophthalmol 2005;20:129-41.

141. LeHoang P, Ozdemir N, Benhamou A, Tabary T, Edelson C, Betuel H, et al. HLA-A29.2 subtype associated with birdshot retinochoroidopathy. Am J Ophthalmol 1992;113:33-5. 142. Abad S, Terrada C, Trad S, Sène D, Bielefeld P, Saadoun D, et al. [Management of uveomeningitis in internal medicine: Proposal for a diagnostic work-up]. Rev Med Interne 2016;37:25-34.

143. Sakata VM, da Silva FT, Hirata CE, de Carvalho JF, Yamamoto JH. Diagnosis and classification of Vogt-Koyanagi-Harada disease. Autoimmun Rev 2014;13:550-5.

144. Abu El-Asrar AM, Abouammoh M, Al-Mezaine HS. Tuberculous uveitis. Int Ophthalmol Clin 2010;50:19-39.

145. Sève P, Kodjikian L, Adélaïde L, Jamilloux Y. Uveitis in adults: What do rheumatologists need to know? Joint Bone Spine 2015;82:308-14.

146. Sève P, Kodjikian L, editors. Oeil et Maladies systémiques. Lavoisier. Paris; 2014. 


\section{Figure legends}

Figure 1. Anatomy of the eye and anatomic patterns of uveitis. Anterior uveitis: iritis, iridocyclitis; intermediate uveitis: pars planitis, posterior cyclitis, hyalitis; posterior uveitis: focal or diffuse choroiditis, chorioretinitis, retinochoroiditis, retinitis, neuroretinitis; panuveitis: involvement of all three segments of the eye [145].

Figure 2. Strategy for the etiologic diagnosis of uveitis. From [27]. 


\section{Figure 1.}
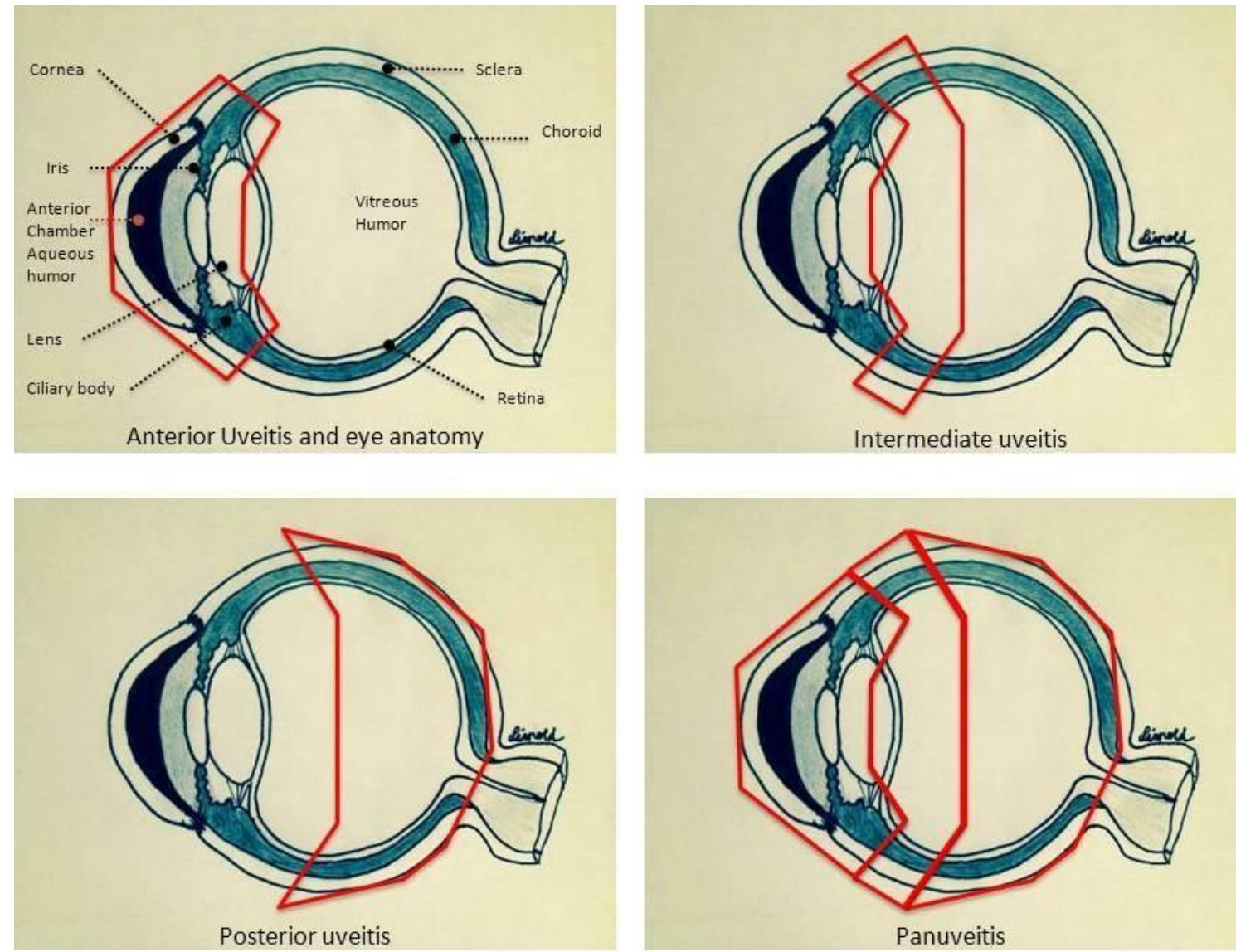


\section{Figure 2.}

Ophthalmology Consultation +/- Internist Consultation

Determination of the anatomic type of uveitis

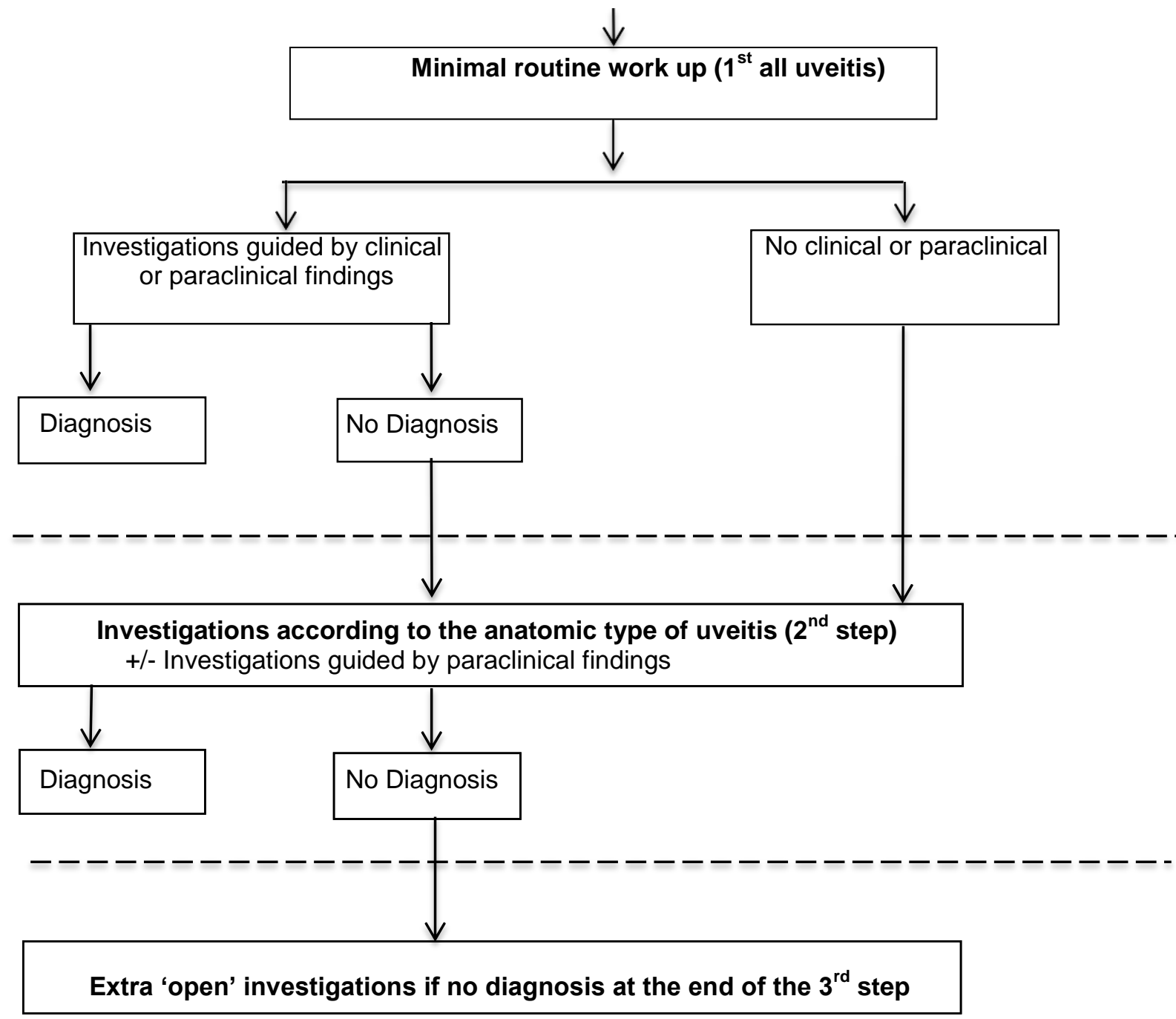


Table 1. Main causes of uveitis reported in Western studies. The most common causes (>0.5\%) are indicated in bold type [14-18,21-23,27].

Etiology Specific causes

Infectious diseases Bacterial: syphilis, tuberculosis, Lyme disease, cat-scratch disease, rickettsiosis, leptospirosis, brucellosis, Whipple's disease, chlamydiosis

Parasitic: toxoplasmosis, toxocariasis, onchocerciasis, cysticercosis

Viral: herpes virus, CMV, HTLV-1, Dengue, West-Nile virus, Rift valley fever, chikungunya

Fungal: candidiasis, histoplasmosis, aspergillosis, cryptococcosis

Inflammatory diseases HLA-B27-associated uveitis

Chronic inflammatory bowel disease

Sarcoidosis

Behçet disease

Vogt-Koyanagi-Harada disease

Multiple sclerosis

Juvenile idiopathic arthritis

Tubulointerstitial nephritis and uveitis (TINU syndrome)

Celiac disease

Systemic lupus erythematosus, systemic vasculitis

Blau syndrome, cryopyrine-associated periodic syndromes

Common variable immunodeficiency

Pseudo-uveitis Trauma, intraocular foreign body

Tumors (oculocerebral lymphoma, melanoma, retinoblastoma, 
metastases)

Ophthalmologic

entities

Drug-induced uveitis

\section{Birdshot chorioretinopathy}

Multifocal choroiditis

Pars planitis

Fuchs heterochromic cyclitis

Phacoantigenic uveitis

Posner-Schlossman syndrome

White dots syndrome (placoid epitheliopathy, serpiginoid

choroiditis)

Sympathetic ophthalmia

Rifabutin

Biphosphonates

Anti-tumor necrosis factor- $\alpha$

IFN $-\alpha$ or $-\beta$

BCG therapy 
Table 2. Etiologic orientation according to the anatomic location of uveitis. The less common causes are indicated in italics [17,23,27,146].

\begin{tabular}{|c|c|}
\hline Anatomic type & Etiologies \\
\hline Acute unilateral anterior uveitis & $\begin{array}{l}\text { HLA-B27-associated uveitis } \\
\text { Uveitis related to herpes virus infection (HSV, VZV, } \\
\text { CMV) }\end{array}$ \\
\hline Acute bilateral anterior uveitis & $\begin{array}{l}\text { Drugs (rifabutin, biphosphonates), infections } \\
\text { (poststreptococcal uveitis), Tubulointerstitial nephritis and } \\
\text { uveitis (TINU syndrome), HLA-B27-associated uveitis, } \\
\text { Kawasaki disease }\end{array}$ \\
\hline Chronic anterior uveitis & \\
\hline $\begin{array}{l}\text { *Granulomatous } \\
* \text { Non-granulomatous }\end{array}$ & $\begin{array}{l}\text { Sarcoidosis, tuberculosis, syphilis, herpes virus } \\
\text { As above + spondyloarthritis, juvenile idiopathic arthritis, } \\
\text { Behçet, Fuchs heterochromic cyclitis }\end{array}$ \\
\hline Intermediate uveitis & $\begin{array}{l}\text { Sarcoidosis, multiple sclerosis } \\
\text { Oculocerebral lymphoma (>40 years-old) } \\
\text { Lyme disease, syphilis }\end{array}$ \\
\hline Posterior uveitis & \\
\hline $\begin{array}{l}\text { *Focal chorioretinitis } \\
\text { *Diffuse choroiditis }\end{array}$ & $\begin{array}{l}\text { Toxoplasmosis } \\
\text { Sarcoidosis Behcet Birdshot chorioretinonathy hernes }\end{array}$ \\
\hline *Retinal vasculitis & $\begin{array}{l}\text { virus, syphilis, tuberculosis, Vogt-Koyanagi-Harada } \\
\text { disease } \\
\text { Behçet, sarcoidosis, syphilis, multiple sclerosis }\end{array}$ \\
\hline Panuveitis & $\begin{array}{l}\text { Sarcoidosis, Behçet } \\
\text { Bacterial, syphilis, herpes virus, toxoplasmosis }\end{array}$ \\
\hline
\end{tabular}


Table 3. Investigations guided by the anatomic type of uveitis.

\begin{tabular}{|c|c|}
\hline Anatomic type of uveitis & Investigations \\
\hline All types of uveitis & $\begin{array}{l}\text { Full blood count } \\
\text { ESR, CRP } \\
\text { Tuberculin skin test } \\
\text { Syphilis serology } \\
\text { Chest X-ray }\end{array}$ \\
\hline Acute anterior uveitis (non-granulomatous) & $\begin{array}{l}\text { HLA-B27 } \\
\text { Sacroiliac imaging if insidious back pain }\end{array}$ \\
\hline $\begin{array}{l}\text { Unexplained acute anterior granulomatous } \\
\text { uveitis }\end{array}$ & $\begin{array}{l}\text { Anterior chamber tap (PCR herpes) after } \\
\text { HSV, VZV and CMV serology }\end{array}$ \\
\hline Chronic uveitis & $\begin{array}{l}\text { ACE } \\
\text { IGRA } \\
\text { Chest CT scan }\end{array}$ \\
\hline $\begin{array}{l}* \text { Chronic intermediate or posterior uveitis } \\
\text { (>40 years-old) }\end{array}$ & $\begin{array}{l}\text { Brain MRI } \\
\text { Toxoplasma serology if focal retinitis }\end{array}$ \\
\hline *Bilateral papillary edema & Lumbar puncture \\
\hline *Intermediate uveitis (>40 years-old) & Anterior chamber tap: interleukin-10, -6 \\
\hline * Corticoresistant uveitis & $\begin{array}{l}\text { Anterior chamber tap: cytology, } \\
\text { interleukins, herpes PCR, M. tuberculosis } \\
\text { PCR, universal PCR } \\
\text { Vitrectomy if lymphoma suspected }\end{array}$ \\
\hline
\end{tabular}

ACE: angiotensin-converting enzyme; BAL: bronchoalveolar lavage; CMV: cytomegalovirus; CRP: C-reactive protein; CT: computerized tomography; ESR: erythrocyte sedimentation rate; HLA: human leucocyte antigen; HSV: herpes simplex virus; IGRA: interferon- $\gamma$ release 
assay; PCR: polymerase chain reaction; MRI: magnetic resonance imaging; VZV: varicella zoster virus. 
Table 4. Recommended investigations according to clinical and/or paraclinical features in unexplained uveitis.

\begin{tabular}{|l|l|}
\hline Investigations & Indications \\
\hline Salivary gland biopsy & Hilar and/or mediastinal adenopathies \\
& High ACE \\
\hline Lumbar puncture & Ocular lymphoma, multiple sclerosis or suspected \\
& Vogt-Koyanagi-Harada disease \\
& Neurologic signs \\
\hline 18 F-fluorodeoxyglucose PET & Unexplained uveitis (suggestive of sarcoidosis) \\
& $>50$ years-old \\
& Synechia \\
& Hilar and/or mediastinal adenopathies \\
\hline Bronchoalveolar lavage & Abnormal chest CT scan \\
& Unexplained chronic posterior uveitis requiring \\
& systemic treatment \\
\hline
\end{tabular}

ACE: angiotensin-converting enzyme; CT: computed tomography; PET: positron emission tomography 